\title{
THE EFFECT OF SIX POSTHARVEST MANAGEMENT REGIMES ON RIPE ROTS OF 'HASS' AVOCADO
}

\author{
K.R. EVERETT ${ }^{1}$ and L. KORSTEN ${ }^{2}$ \\ ${ }^{1}$ Horticulture and Food Research Institute of New Zealand, \\ Mt Albert Research Centre, Private Bag 92169, Mt Albert, Auckland, New Zealand \\ ${ }^{2}$ Department of Microbiology and Plant Pathology, University of Pretoria, \\ Republic of South Africa
}

\begin{abstract}
The effect of six postharvest management regimes on the incidence and severity of 'Hass' avocado ripe rots was compared in 1996. Fruit from a stepped temperature regime had most anthracnose. Two "sea shipping" regimes tested resulted in fewer rots than all other treatments, including "air shipping". A two day delay in application of prochloraz significantly reduced control of stem end rots. Fruit subjected to no coolstorage, delayed coolstorage and stepped temperatures had the most rots overall. The amount of time fruit was at $6^{\circ} \mathrm{C}$ was significantly inversely related to disease incidence.
\end{abstract}

Keywords: avocado, postharvest, diseases, temperature, cool chain.

\section{INTRODUCTION}

Postharvest rots are considered to be an important problem for avocado (Persea americana) in New Zealand. Colletotrichum acutatum Simmonds ex Simmonds, Colletotrichum gloeosporioides (Penz.) Penz. \& Sacc. (teleomorph Glomerella cingulata (Stoneman) Spauld. \& H. Schrenk), Botryosphaeria parva Pennycook \& Samuels, Botryosphaeria dothidea (Mougeot ex Fries) Cesati \& de Notaris and Phomopsis sp. are the fungi predominantly isolated from fruit with postharvest rots (Hartill 1991). Each of these fungi can cause either stem end rots or anthracnose which become symptomatic after harvest. Despite the use of optimised storage and ripening temperatures, under experimental conditions approximately $20 \%$ of 'Hass' fruit were affected by postharvest rots (Hopkirk et al. 1994). A survey in the Sydney marketplace showed that $41 \%$ of 'Hass' fruit from New Zealand were unacceptable, due to anthracnose (25\%) and stem end rots (21\%) (Ledger et al. 1993; Ledger and Barker 1995). Some fruit had both stem end rots and anthracnose.

New Zealand fruit is generally exported, either by air or by sea, without emphasis on maintenance of the cool chain. Breaks in the cool chain include leaving fruit sitting on the tarmac at the airport until being transported in uncooled trucks to the marketplace. Refrigerated trucks are generally not used by exporters to transport fruit to the sea or air port in New Zealand. In contrast, this process is strictly controlled in South Africa. South African fruit has less of a rot problem when compared to New Zealand fruit, despite a longer transit time to market (Everett and Korsten 1994). A total of 28 days shipping time is required for South African fruit to Europe compared with 5 days for New Zealand fruit to Australia. The aim of this work was to compare the South African stepped temperature regime, with no breaks in the cool chain, and several New Zealand postharvest management regimes for their effect on the incidence and severity of postharvest rots.

\section{METHODS}

Three trays per treatment (69 fruit, 23 fruit per tray) of 'Hass' avocado fruit were obtained from a commercial packing line (Trevallyans Packhouse) in Te Puke, New Zealand immediately after picking and packing in January 1996. There were six postharvest management regimes (Table 1). All treatments were exposed to 
approximately $20^{\circ} \mathrm{C}$ for 3 hours while they were picked and packed. Prochloraz ( 450 $\mathrm{g} /$ litre, Sportak $45 \mathrm{EC}$ ) was applied where indicated by dipping fruit in a $5.5 \mathrm{ml} / \mathrm{litre}$ suspension for 2 mins.

TABLE 1: Simulation of postharvest management regimes for 'Hass' avocado fruit exported from South Africa and New Zealand by sea and air.

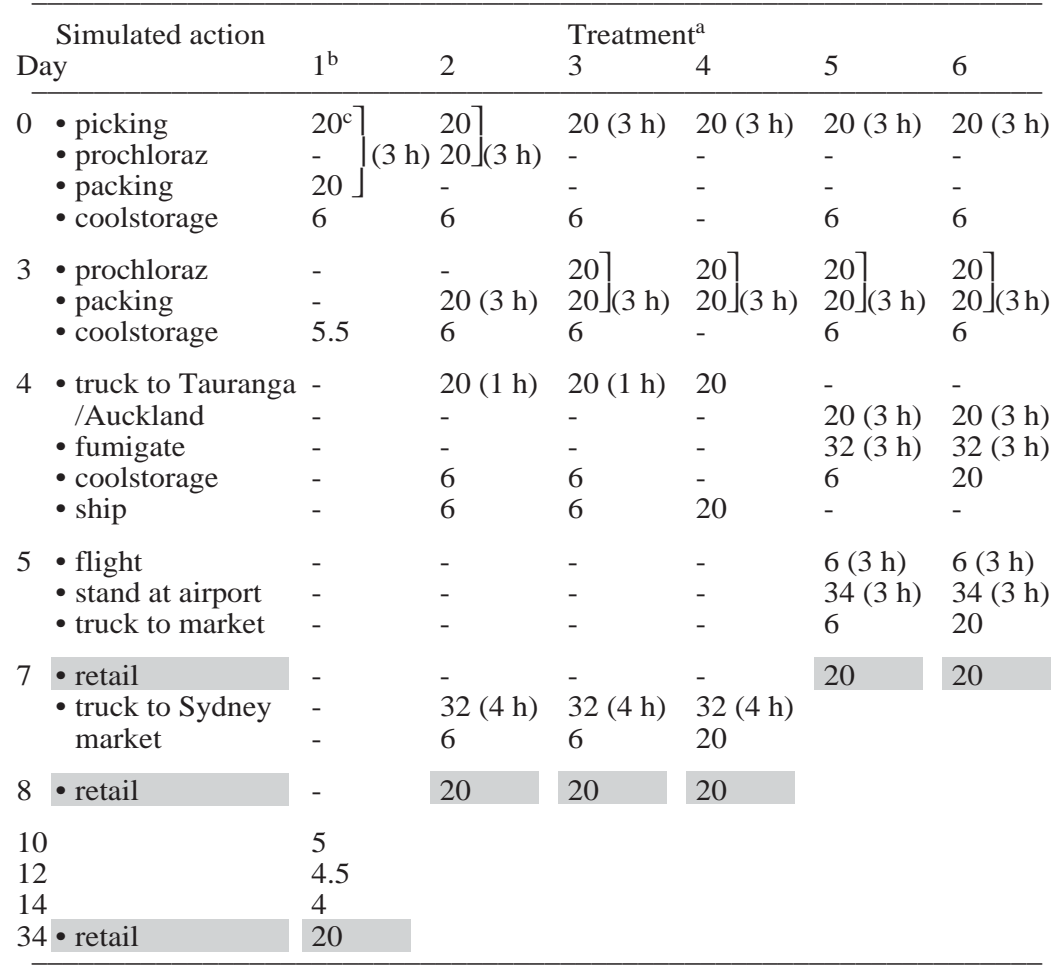

a Treatment $1=$ South African shipping regime; Treatment $2=$ New Zealand shipping regime, prochloraz applied immediately after harvest; Treatment $3=$ New Zealand shipping regime, prochloraz applied after 2 days coolstorage; Treatment $4=\mathrm{NZ}$ shipping regime with no coolstorage; Treatment $5=\mathrm{New}$ Zealand air shipment regime;Treatment $6=\mathrm{New}$ Zealand air shipment regime with less coolstorage.

${ }^{\mathrm{b}}$ Values are temperature in ${ }^{\circ} \mathrm{C}$ and figures in parentheses are the duration of each temperature regime if less than 24 hours. (indicates simulated action not taken.

${ }^{\mathrm{c}}$ Temperatures of 20 indicate fruit were at ambient, approximately $20^{\circ} \mathrm{C}$.

After each treatment was completed, fruit were placed at approximately $20^{\circ} \mathrm{C}$ (Figure 1), evaluated for softness by gentle hand squeezing on a $0-10$ scale $(0=$ hard, $5=$ ready to eat, $10=$ totally soft) and assessed when fruit were ready to eat. Fruit were assessed internally for stem end rots and anthracnose. All assessments were made on a 0-10 scale, $0=$ healthy and 10 indicating entire fruit decay (Korsten et al. 1995). Disease incidence data were arcsine transformed prior to ANOVA, and the means separated by Fisher's protected least significant difference test (LSD). The severity of the lesions on the fruit with rots was similarly analysed but data were not transformed. 


\section{RESULTS}

The incidence of anthracnose rots in Treatment 1 was significantly $(\mathrm{P}<0.05)$ greater than in all other treatments (Figure 2a). No other treatments had a significant effect on either incidence or severity of anthracnose.

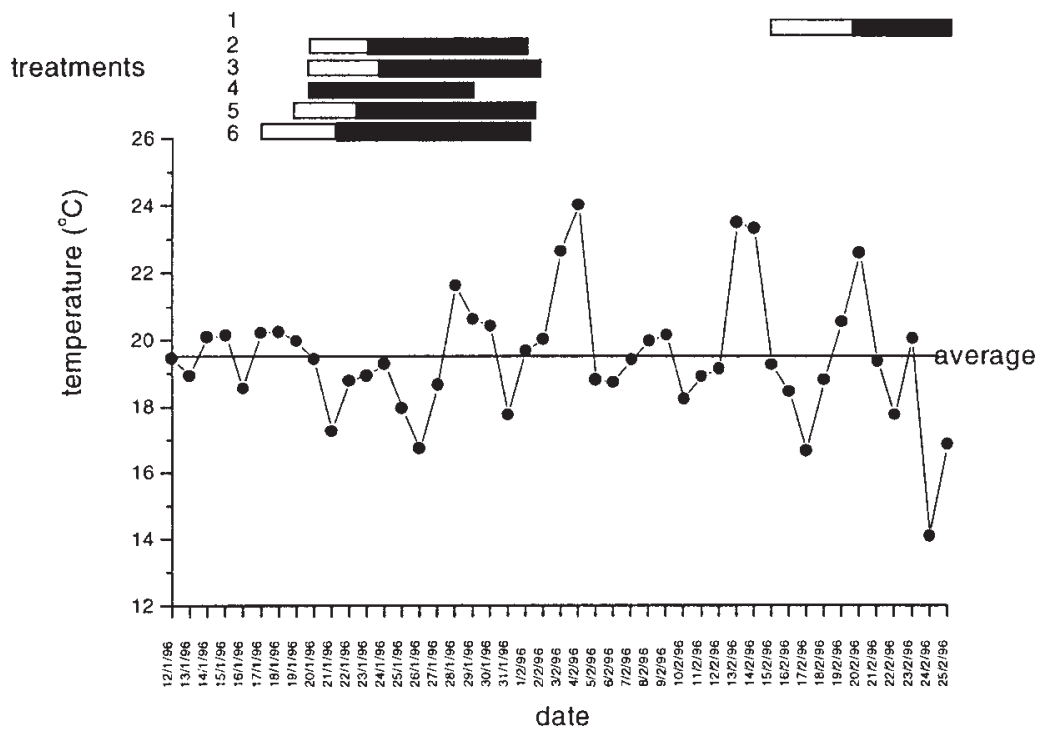

FIGURE 1: Average ambient daily temperature during the experiment $(-0)$. The line at $19.5^{\circ} \mathrm{C}$ is the average for the entire period. Open bars indicate when each of treatments 1-6 were removed from simulated shipping and placed at ambient. Solid bars indicate when fruit were assessed for rots.

a)

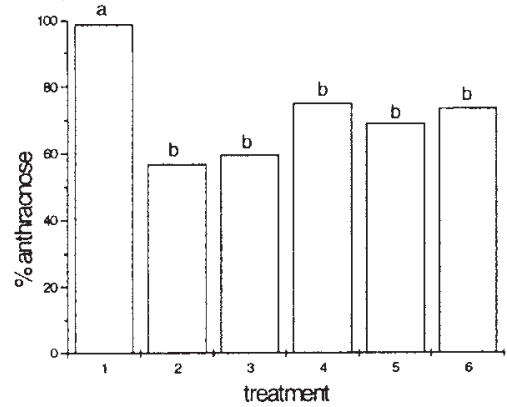

b)

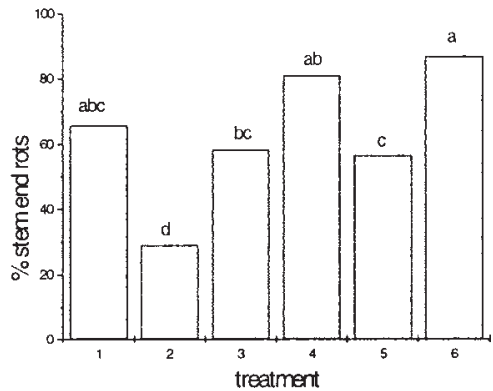

FIGURE 2: Incidence of a) anthracnose and b) stem end rots of 'Hass' avocados under six postharvest management regimes. For details of treatments, see Table 1. Columns with the same letter are not significantly $(\mathbf{P}<0.05)$ different according to Fishers' Protected LSD test. a) anthracnose, $\mathrm{LSD}=19.6$, b) stem end rots, $\mathrm{LSD}=22.4$. Data are arcsine transformed. 
The incidence of stem end rots was significantly $(\mathrm{P}<0.01)$ less in Treatment 2 compared to the other treatments (Figure 2b). There was no significant difference in stem end rot severity between treatments. Most stem end rots occurred in fruit from Treatment 6 , followed by Treatments 4, 1, 3 then 5 . The differences were significant $(\mathrm{P}<0.01)$ between fruit from Treatment 6 and Treatments 3 and 5.

When the times that fruit were stored at three broad temperature bands used in the experiment were compared, $\left(6^{\circ} \mathrm{C}, \mathrm{c} .20^{\circ} \mathrm{C}\right.$ and $\left.>30^{\circ} \mathrm{C}\right)$, stepwise regression analysis showed that only length of time fruit was at $6^{\circ} \mathrm{C}$ had any significant effect on incidence of stem end rots $\left(\mathrm{P}<0.01, \mathrm{R}^{2}=53.9 \%\right.$, Figure 3$)$. The relationship was negative, ie the greater the time spent at $6^{\circ} \mathrm{C}$, the less rots. The effect of length of time at $<6^{\circ} \mathrm{C}$ was difficult to include in this analysis as only fruit from Treatment 1 was coolstored below $6^{\circ} \mathrm{C}$.

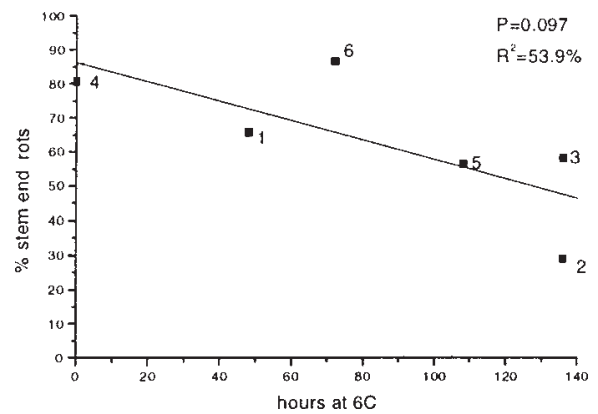

FIGURE 3: Relationship between total hours at $6^{\circ} \mathrm{C}$ and percent stem end rots (arcsine transformed) of 'Hass' avocado fruit.

\section{DISCUSSION}

Incidence and severity of anthracnose were not affected by any of the management regimes except for Treatment 1, without any breaks in the cool chain, which appeared to increase incidence. These fruit were coolstored for a total of 32 days compared to 5-8 days with other treatments, and unlike fruit from all other treatments were not prochloraz dipped, according to the practice in South Africa. Both factors probably contributed to the number of rots. Climatic and soil differences between South Africa and New Zealand (Everett 1996) may also have contributed to this result. The outcome for Treatment 1 suggests a postharvest stepped temperature regime designed for South African fruit may not be applicable in New Zealand conditions.

When prochloraz was applied immediately after harvest (Treatment 2), stem end rots were significantly reduced compared to Treatment 3 . The only difference between treatments 2 and 3 was the timing of the prochloraz dip. When there was a 2 day delay in application of prochloraz in Treatment 3 , stem end rots were not reduced significantly compared with other treatments. This suggests that fungi penetrated the stem end during that 2 day interval and were thus not controlled by delayed applications of prochloraz.

Treatments 5 and 6 were similar, except fruit in Treatment 5 were coolstored for a longer time. Despite the temperature fluctuations undergone by fruit from Treatment 5 , which included the high temperature fumigation step, the inclusion of additional coolstorage led to a lower incidence of stem end rots compared to Treatment 6. Treatment 4 fruit were not coolstored at all, and stem end rot incidence was high. These trends tend to suggest that coolstorage was important in reducing stem end rot incidence. In fact, when the cumulative temperature data were compared (Figure 3), only time at $6^{\circ} \mathrm{C}$ had a significant effect on disease incidence. These results suggest 
that coolstorage at $6^{\circ} \mathrm{C}$ reduced stem end rot incidence, a conclusion supported by previous results (Everett et al. 1993). However, this difference was only significant at the $10 \%$ level, and as our treatments were not selected to examine single effects, this observation needs to be verified. Surprisingly, time at $>32^{\circ} \mathrm{C}$ did not appear to result in a significant increase in stem end rot incidence. It seems that exposure to these high temperatures was not of sufficient length to have an effect, or otherwise high temperatures may be detrimental to disease development. The effect of storing fruit at approximately $20^{\circ} \mathrm{C}$ was probably insignificant compared with the other effects, such as timing of prochloraz application and total time at $6^{\circ} \mathrm{C}$. Hopkirk et al. (1994) found that storage of fruit at temperatures close to the final ripening temperature could result in fewer rots.

Our results indicate that the South African stepped temperature regime tested was not applicable to New Zealand fruit, prochloraz needs to be applied immediately after harvest to effectively control rots, and that coolstorage may be important in reducing rots. We did not show that maintenance of the cool chain is necessary to reduce rot incidence or severity. Comparison with a treatment in which fruit is coolstored for 58 days with no breaks in the cool chain is required before any conclusions can be made concerning maintenance of the cool chain. Further experimentation is also required to investigate the effect of both high and low temperature on disease incidence and severity.

\section{ACKNOWLEDGEMENTS}

Jurg Bezuidenhout, Westfalia Estate, South Africa, for provision of details of the stepped temperature regime as used for 'Hass' fruit from KwaZulu/Natal exported to Europe, and to Alistair Hawkey, Norrie Lees, Jonathan Cutting and Ron Bailey for details of postharvest practices in New Zealand. Also to Philippa Roderick for technical assistance, Nihal deSilva for statistical advice, and Yvonne Roberts for assistance with data entry.

\section{REFERENCES}

Everett, K.R., 1996. Sauvignon blanc, climate and ignoble rots.Avocado Scene 9: 1719.

Everett, K.R., Forbes, S.K. and White, A., 1993. Evaluation of Bacillus subtilis (isolate B 1) as a biocontrol agent for avocado ripe rot.HortResearch Client Report No. 93/124.

Everett, K.R. and Korsten, L., 1994. Comparing the South African and New Zealand avocado industries. The N.Z. Avo. Growers Assn Inc. Scientific Research and Technical Supplement 20:39-47.

Hartill, W.F.T., 1991. Post-harvest disease of avocado fruits in New Zealand N.Z. J. Crop Hort. Sci. 19: 297-305.

Hopkirk, G., White, A., Beever, D.J. and Forbes, S.K. 1994. Influence of postharvest temperatures and the rate of fruit ripening on internal postharvest rots and disorders of New Zealand 'Hass' avocado fruit. N.Z. J. Crop and Hort. Sci. 22: 305-311.

Korsten, L. , De Jager, E.S., De Villiers, E.E., Kotze, J.M. and Wehner, F.C., 1995. Evaluation of bacterial epiphytes isolated from avocado leaf and fruit surfaces for biocontrol of avocado postharvest diseases. Plant Dis. 79: 1149-1156.

Ledger, S., Campbell, T., Banks, A., Atkinson, I., Kernot, I. and Fullelove, G., 1993. Internal quality of avocados in retail shops. Avoman Project Report: 1-7.

Ledger, S.N. and Barker, L.R. 1995. Black avocados- the inside story. In: Proc. Australian Avocado Growers' Federation Conference 95 'The Way Ahead', Department of Agriculture Western Australia, Fremantle: 71-77. 